\title{
Thalassemia and Priapism: A Literature Review of a Rare Association
}

\author{
Sundus Sardar ${ }^{1}$, Elrazi A. Ali ${ }^{1}$, Mohamed A. Yassin ${ }^{2}$ \\ 1. Internal Medicine, Hamad Medical Corporation, Doha, QAT 2. Department of Hematology, National Centre for \\ Cancer Care and Research, Hamad Medical Corporation, Doha, QAT
}

Corresponding author: Sundus Sardar, ssardar@hamad.qa

\begin{abstract}
Thalassemia is a hematologic disorder caused by genetic mutation resulting in impaired hemoglobin chain production. Patients with thalassemia commonly experience complications such as anemia, blood transfusion-related issues, hepatic or cardiac involvement, and psychosocial impacts. Rarely, priapism has been associated with thalassemia as an initial presentation or subsequently occurring at any time in the disease course. Our literature review summarizes the reported cases of thalassemia-associated priapism and delves into underlying mechanisms of its pathophysiology and appropriate management.
\end{abstract}

Categories: Internal Medicine, Hematology

Keywords: thalassemia, priapism, hematology

\section{Introduction And Background}

Thalassemia is a hematologic disorder caused by mutations in the genes coding for hemoglobin chains. The most common causes of genetic disorders in humans are mutations within the $\beta$-globin gene, of which 350 $\beta$-thalassemia mutations have been identified to date [1]. Clinical manifestations of thalassemia are highly variable, ranging from asymptomatic in individuals with mild/silent mutations to mild hypochromic anemia, while other individuals may have life-long transfusion-dependent moderate to severe anemia and multiorgan involvement [2].

Review began 03/21/2021 Review ended 04/03/2021 Published 04/07/2021

(c) Copyright 2021 Sardar et al. This is an open access article distributed under the terms of the Creative Commons Attribution License CC-BY 4.0., which permits unrestricted use, distribution, and reproduction in any medium, provided the original author and source are credited.
Individuals with thalassemia may experience complications, including but not limited to liver fibrosis and cirrhosis, cardiac failure, arrhythmias, and endocrinopathies [3]. Endocrine complications of thalassemia major commonly involve growth hormone and insulin-like growth factor (IGF-1) axis resulting in IGF-1 deficiency associated with growth hormone deficiency [4]. Adrenal abnormalities in patients with thalassemia were appropriately identified with low-dose adrenocorticotropic hormone (ACTH) test rather than standard dose ACTH, deeming it necessary to perform a low-dose ACTH test to identify possible adrenal insufficiency or underlying latent hypocortisolism, especially in thalassemia patients undergoing major surgical procedures $[5,6]$.

Thalassemia patients may rarely present with or subsequently develop priapism, which is defined as a persistent penile erection lasting longer than four hours. Priapism can be classified into ischemic (venoocclusive low flow), non-ischemic (arterial high flow), and stuttering (recurrent episodes) [7]. In most cases, the underlying etiology remains unidentified (primary/idiopathy). Secondary causes of priapism consist of intracavernous injections (iatrogenic); medications; hematological disorders; neurological involvement (spinal shock); trauma to the perineal, penile, or pelvic regions; infection (malaria, spider toxins); and metabolic disorders [7]. Priapism is rarely reported in patients with thalassemia. Clitoral priapism has been reported in other diseases; however, there are no cases reported in association with thalassemia. The underlying pathophysiology is not clear; however, the mechanism for the development of priapism is attributed to deranged autoregulation of penile circulation due to the nitric oxide pathway and phosphodiesterase enzyme activity [7].

\section{Review}

We conducted an extensive review of case reports, case series, and observational studies on thalassemia from 1986 to 2020 on PubMed, Scopus, and Google Scholar search engines to determine priapism's incidence as an initial presentation or subsequently occurring during the thalassemia disease course. All articles documenting priapism associated with thalassemia were included. Any cases of priapism associated with sickle cell beta-thalassemia or related to other diseases or medications were excluded (Figure 1). 


\section{Cureus}
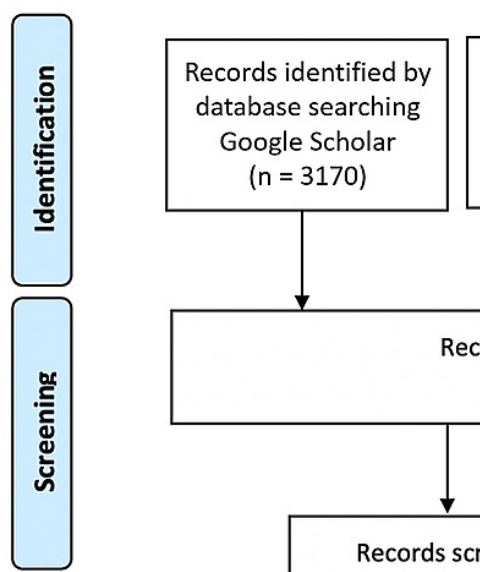

Records identified through database searching PubMed $(n=3170)$

$(n=60)$

through database

searching Scopus $(n=28)$
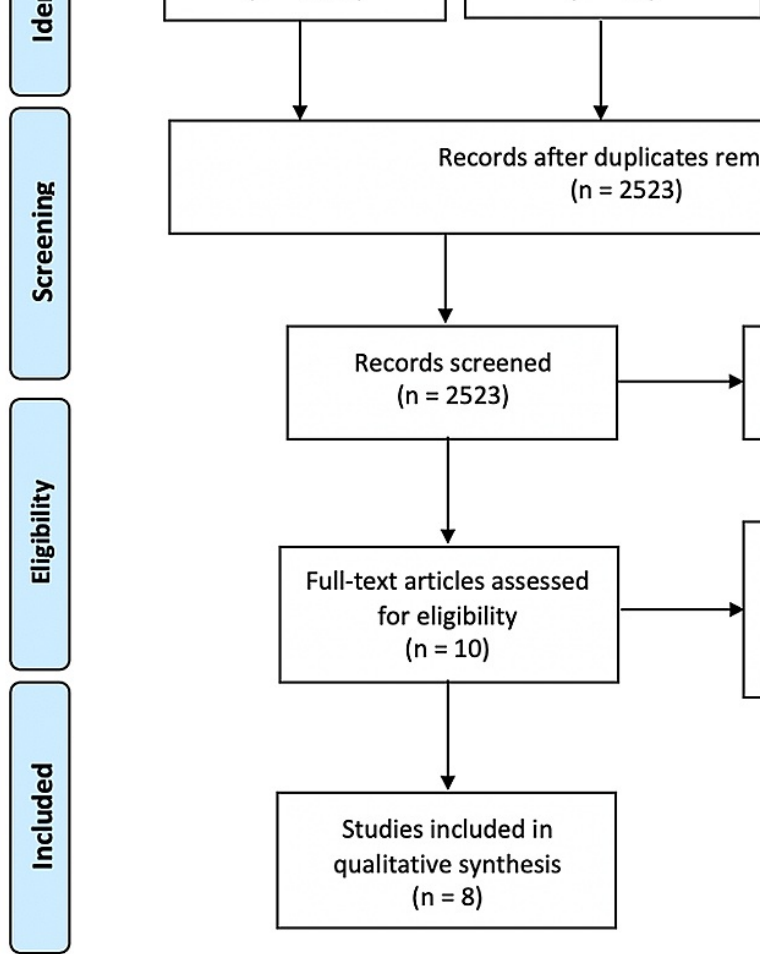

Records after duplicates removed

$(n=2523)$

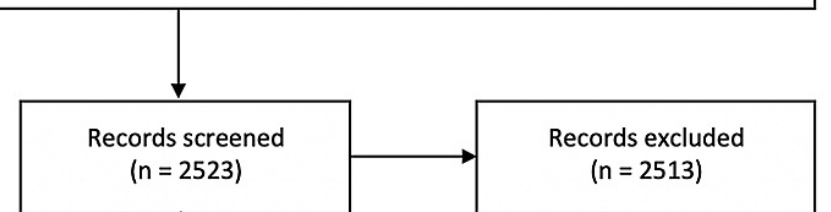
with reasons

$(n=2$, sickle cell beta thalassemia)

FIGURE 1: The PRISMA flow diagram illustrating the cases of thalassemia associated with priapism as initial presentation or subsequent development during disease course.

Abbreviation: PRISMA, Preferred Reporting Items for Systematic Reviews and Meta-Analyses.

Eight appropriate articles (total nine cases) of priapism associated with thalassemia were identified [8-15]. Table 1 elicits thalassemia subtype, hematological parameters, management of priapism, and clinical outcome. Cases are arranged chronologically. Age groups reported range from 15 to 42 years. 


\section{Cureus}

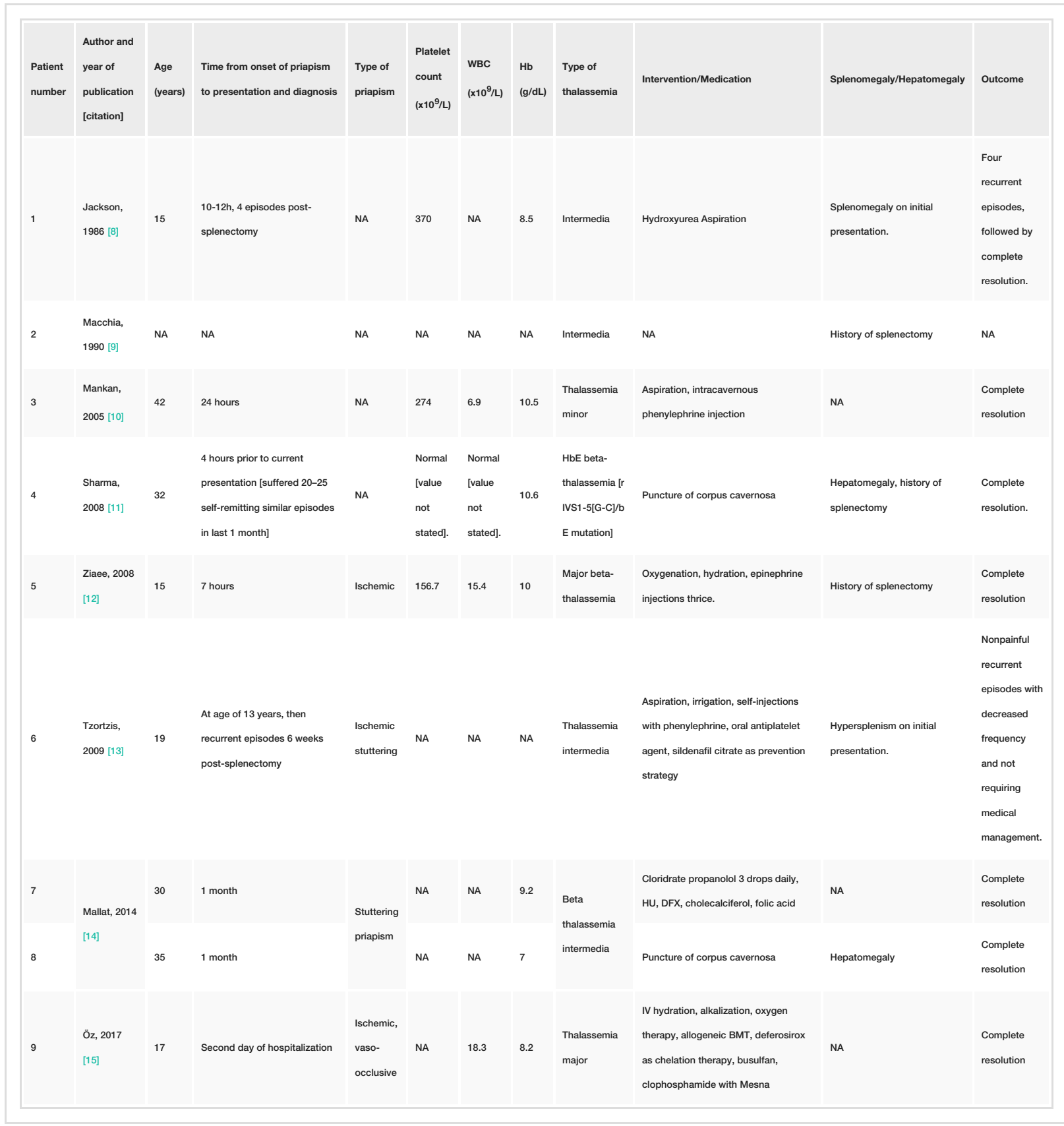

TABLE 1: Reported cases of priapism associated with thalassemia, arranged by chronological order

WBC, white blood cell; Hb, hemoglobin; HbE, hemoglobin E; NA, not applicable; HU, hydroxyurea; DFX, deferasirox; IV, intravenous; BMT, bone marrow transplant.

Thalassemia and its associated complications adversely impact the quality of life of affected individuals, including adverse effects on their overall health, school performance, mental health status, and the physical, social and psychological aspects of their lives [16,17]. Additionally, thalassemic patients with priapism as a complication or presenting concern experience further worsening of quality of life due to impairment of sexual function and the possible risk of penile fibrosis and, subsequently, permanent erectile dysfunction. Thus far, there are no reports of cases with thalassemia-associated clitoral priapism.

With advancements in thalassemia management and identifying factors impacting the quality of life, many patients have good outcomes and are successfully married [18]. In adolescents and young male patients affected with chronic disease (e.g., hemoglobinopathies, failure of pubertal growth, absence or delay of sexual development), infertility and sexual dysfunction are well-established disturbances secondary to hypogonadism and impaired spermatogenesis [19]. Infertility negatively impacts these individuals' future 
quality of life and is also a predictor of stress in any existing or forthcoming relationships. In these patients, the impact of priapism on quality of life, sexual function, and physical wellness can be evaluated and quantified using the Priapism Impact Profile questionnaire [20].

While priapism is rarely seen in thalassemic patients, a postulated mechanism proposes a cellular mechanism owing to increased blood viscosity as demonstrated by thrombocytosis or elevated nucleated red blood count (NRBC) [21]. Moreover, intravascular stasis may cause thrombotic occlusion of efferent venules in the corpora cavernosa, resulting in intracorporal sludging, fibrosis, and impairment of the erectile mechanism. Another proposed functional mechanism involves altering the molecular determinants of erectile response due to abnormal nitric oxide activity in the penile tissue, downregulation of phosphodiesterase- 5 activity, and the overresponse of the penile smooth muscle. In the hemolytic state of thalassemia, nitric oxide hemostasis is impaired due to nitric oxide consumption, resulting in vasoconstriction [21].

Priapism is a rare entity in the spectrum of thromboembolic disease. Splenectomized thalassemic patients are predisposed to developing a thromboembolic event (TEE) due to elevated NRBC, thrombocytosis, and platelet aggregation. Moreover, factors associated with earlier development of TEE post-splenectomy include transfusion naivety, thrombocytosis, and elevated NRBC due to the thrombogenic potential of negatively charged membranes [22].

As evidenced by our data, most thalassemia and priapism patients had low hemoglobin values (mean hemoglobin level was $9.14 \pm 1.32 \mathrm{~g} / \mathrm{dL}$ ). Thus far, in the literature, $55.5 \%$ (five out of nine cases) of thalassemic patients with priapism were diagnosed as thalassemia intermedia. All cases of priapism reported in thalassemic patients had complete resolution. A higher prevalence of priapism is evident in postsplenectomized thalassemic patients $[8,9,11,13]$.

The management of priapism in thalassemic patients includes conservative management similar to that in individuals with sickle cell disease, oxygenation, hydration, and analgesics. Further treatment consists of a supertransfusion regimen, erythropoiesis, irrigation, and intracavernosal alpha-agonist injections with phenylephrine every five minutes after aspiration of $10 \mathrm{~mL}$ to $20 \mathrm{~mL}$ of blood [23]. For cases of priapism refractory to conservative treatment modalities, the next therapeutic step involves surgical intervention and spongiocavernous shunt insertion [24].

Long-term complications of priapism in thalassemic individuals include penile fibrosis and erectile dysfunction, with discernable negative impacts on quality of life due to impaired sexual function and troublesome reproductive issues. A recent case reported treatment of erectile dysfunction in thalassemic men with the administration of transurethral E1-prostaglandins such as alprostadil as an effective, noninvasive therapy [25].

\section{Conclusions}

Priapism is a rare presentation in patients with thalassemia with a significant impact on these individuals' quality of life. While only a few cases have been reported, priapism is documented as a rare association more commonly seen in thalassemia intermedia and post-splenectomized thalassemic individuals. Early identification and appropriate management of priapism in thalassemic patients are essential to prevent longstanding erectile dysfunction.

\section{Additional Information \\ Disclosures}

Conflicts of interest: In compliance with the ICMJE uniform disclosure form, all authors declare the following: Payment/services info: All authors have declared that no financial support was received from any organization for the submitted work. Financial relationships: All authors have declared that they have no financial relationships at present or within the previous three years with any organizations that might have an interest in the submitted work. Other relationships: All authors have declared that there are no other relationships or activities that could appear to have influenced the submitted work.

\section{References}

1. De Sanctis V, Kattamis C, Canatan D, et al.: $\quad \beta$-thalassemia distribution in the old world: an ancient disease seen from a historical standpoint. Mediterr J Hematol Infect Dis. 2017, 9:e2017018. 10.4084/MJHID.2017.018

2. Khan AM, Al-Sulaiti AM, Younes S, Yassin M, Zayed H: The spectrum of beta-thalassemia mutations in the 22 Arab countries: a systematic review. Expert Rev Hematol. 2021, 14:109-122. 10.1080/17474086.2021.1860003

3. Kanbour I, Chandra P, Soliman A, et al.: Severe liver iron concentrations (LIC) in 24 patients with $\beta$ thalassemia major: correlations with serum ferritin, liver enzymes and endocrine complications. Mediterr J Hematol Infect Dis. 2018, 10:e2018062. 10.4084/MJHID.2018.062

4. De Sanctis V, Soliman AT, Candini G, et al.: Insulin-like growth factor-1 (IGF- 1): demographic, clinical and laboratory data in 120 consecutive adult patients with thalassaemia major. Mediterr J Hematol Infect Dis. 
2014, 6:e2014074. 10.4084/MJHID.2014.074

5. Soliman AT, Yassin M, Majuid NM, Sabt A, Abdulrahman MO, De Sanctis V: Cortisol response to low dose versus standard dose (back-to-back) adrenocorticotrophic stimulation tests in children and young adults with thalassemia major. Indian J Endocrinol Metab. 2013, 17:1046-52. 10.4103/2230-8210.122620

6. De Sanctis V, Soliman AT, Canatan D, et al.: An ICET-A survey on occult and emerging endocrine complications in patients with $\beta$-thalassemia major: conclusions and recommendations. Acta Biomed. 2019, 89:481-489. 10.23750/abm.v89i4.7774

7. Burnett AL, Bivalacqua TJ: Priapism: current principles and practice. Urol Clin North Am. 2007, 34:631-42. 10.1016/j.ucl.2007.08.006

8. Jackson N, Franklin IM, Hughes MA: Recurrent priapism following splenectomy for thalassaemia intermedia. Br J Surg. 1986, 73:678. 10.1002/bjs.1800730832

9. Macchia P, Massei F, Nardi M, Favre C, Brunori E, Barba V: Thalassemia intermedia and recurrent priapism following splenectomy. Haematologica. 1990, 75:486-7.

10. Mankan N, Samavedi V, Mazumder S, Razaq M, Gloria F, Maini A: Case report of priapism in a patient with thalassemia minor. Blood. 2005, 106:3820. 10.1182/blood.V106.11.3820.3820

11. Sharma R, Prakash R, Kamboj S, Jain V: Hemoglobin-E beta thalassemia presenting with recurrent priapism-a rare complication. Am J Hematol. 2008, 83:257. 10.1002/ajh.21110

12. Ziaee SA, Javaherforooshzadeh A: Priapism in a 15-year-old boy with major beta-thalassemia . Urol J. 2008, 5:55-6.

13. Tzortzis V, Mitrakas L, Gravas S, Mamoulakis C, Meissner A, Kyriakou D, Melekos MD: Oral phosphodiesterase type 5 inhibitors alleviate recurrent priapism complicating thalassemia intermedia: a case report. J Sex Med. 2009, 6:2068-71. 10.1111/j.1743-6109.2009.01285.x

14. Mallat NS, Wehbe D, Haddad A, et al.: Priapism, an emerging complication in $\beta$-thalassemia intermedia patients. Hemoglobin. 2014, 38:351-4. 10.3109/03630269.2014.960087

15. Öz S, Küpeli S, Sezgin G, Bayram İ: Thalassemia major and priapism: a case report of an adolescent . J Pediatr Hematol Oncol. 2017, 39:e336-e337. 10.1097/MPH.0000000000000846

16. Ansari SH, Baghersalimi A, Azarkeivan A, Nojomi M, Rad AH: Quality of life in patients with thalassemia major. Iran J Ped Hematol Oncol. 2014, 4:57-63.

17. Nashwan AJ, Yassin MA, Babu GD, et al.: Quality of life among adolescents aged 14 to 18 years with betathalassemia major (TM) in Qatar. Acta Biomed. 2018, 89:16-26. 10.23750/abm.v89i2-S.7083

18. Soliman A, Yasin M, El-Awwa A, Osman M, de Sanctis V: Acute effects of blood transfusion on pituitary gonadal axis and sperm parameters in adolescents and young men with thalassemia major: a pilot study. Fertil Steril. 2012, 98:638-43. 10.1016/j.fertnstert.2012.05.047

19. De Sanctis V, Soliman A, Mohamed Y: Reproductive health in young male adults with chronic diseases in childhood. Pediatr Endocrinol Rev. 2013, 10:284-96.

20. Burnett AL, Anele UA, Derogatis LR: Priapism impact profile questionnaire: development and initial validation. Urology. 2015, 85:1376-81. 10.1016/j.urology.2015.02.025

21. Mallat NS, Wehbe D, Haddad A, et al.: Priapism, an emerging complication in $\beta$-thalassemia intermedia patients. Hemoglobin. 2014, 38:351-4. 10.3109/03630269.2014.960087

22. Taher AT, Musallam KM, Karimi M, et al.: Splenectomy and thrombosis: the case of thalassemia intermedia . J Thromb Haemost. 2010, 8:2152-8. 10.1111/j.1538-7836.2010.03940.x

23. Mantadakis E, Cavender JD, Rogers ZR, Ewalt DH, Buchanan GR: Prevalence of priapism in children and adolescents with sickle cell anemia. J Pediatr Hematol Oncol. 1999, 6:518-22.

24. Adeyoju AB, Olujohungbe AB, Morris J, et al.: Priapism in sickle-cell disease; incidence, risk factors and complications - an international multicentre study. BJU Int. 2002, 90:898-902. 10.1046/j.1464410X.2002.03022.x

25. Lombardo T, Giammusso B, Frontini V, D'Arpa S, Pafumi C, Caruso S: Thalassaemic men affected by erectile dysfunction treated with transurethral alprostadil: case report. Hum Reprod. 2000, 15:2375-8. 10.1093/humrep/15.11.2375 